\title{
DA CASA AO CONGRESSO - A INSERÇÃO DAS MULHERES NA POLÍTICA PARTIDÁRIA: AÇÕES AFIRMATIVAS PARA INCLUSÃO FEMININA NOS PARLAMENTOS
}

\author{
Ilton Garcia Costa ${ }^{1}$ \\ Ana Pavanini Navas ${ }^{2}$
}

\section{Resumo}

O artigo trata da participação feminina na política dos partidos de nações democráticas, em especial o Brasil. Será dissertado sobre o percurso emancipatório da mulher nos últimos dois séculos até os dias atuais, tratando da ascensão social da mulher, com ênfase em sua crescente participação na política do país como eleitora e como candidata a um determinado cargo eletivo. Legalmente não há mais diferença de entre o gênero masculino e feminino no que tange ao usufruto de direitos, mas ainda é pequena a participação das mulheres em eleições, sendo poucas as eleitas. Discorrer-se-á sobre ações afirmativas a fim de incluí-las nos parlamentos, promovendo a igualdade material. Os métodos utilizados serão os indutivo, dedutivo, analítico regressivo e revisão bibliográfica.

Palavras-chave: Direitos políticos. Mulheres. Participação. Lei. Inclusão.

\section{INTRODUÇÃO}

Tema com destaque na literatura sociológica e jurídica brasileira dos dias contemporâneos é inclusão social, sendo esta ínsita nos âmbitos, principalmente, da educação (sistema de cotas para ingressos em universidades), trabalhista (cotas para concursos públicos), econômico (programas para diminuição da pobreza e habitacionais), tendo em foco promoção de igualdade material para cumprir o Estado Democrático de Direito. Assim, não basta a igualdade jurídico-formal do plano político, declarada pelo artigo $1^{\circ}$ da Declaração dos Direitos do Homem e do Cidadão, pois ela levou em conta, naquele momento, uma suposta igualdade já contida na sociedade, não atentando às diferenças já existentes até então. Assim, essa igualdade material consiste em propiciar a determinado grupo/sociedade tratamento/meios que possibilite $(\mathrm{m})$ aqueles em ampla desvantagem para obtenção de direitos fazer jus à parcela de prestações do Estado, de maneira lhes sejam diminuídas as dificuldades

\footnotetext{
${ }^{1}$ Pós Doutorando pela Universidade de Coimbra. Professor do Programa de Doutorado, Mestrado e Graduação em Direito na UENP - Universidade Estadual do Norte do Paraná. Líder do Grupo de Pesquisa em Constitucional, Educacional, Relações de Trabalho e Organizações Sociais - GPCERTOS da UENP. E-mail: iltoncosta@uenp.edu.br

${ }^{2}$ Mestranda em Ciências Jurídicas pela UENP.Membro do GPCERTOS - Grupo de Pesquisa em Constituição, Educação, Relações de Trabalho e Organizações Sociais da UENP. E-mail: anapaula.pavanini@gmail.com
} 
de acesso às prestações estatais e usufruto dos direitos constitucionalmente assegurados. Os sujeitos beneficiados são, normalmente, escolhidos a partir do critério econômico e racial (pobres, negros e índios). No entanto, pouco se fala em inclusão política, seja direcionada a esses beneficiários retromencionados, seja direcionado à participação da mulher na política partidária de uma determinada nação.

O foco do presente estudo é a inclusão da mulher na política partidária, maneiras de promover esta ação diante da analogia de outras políticas de integração cidadãs, sendo este o motivo que se levou a introduzir este trabalho falando sobre sistemas de cotas e programas sociais. Destaca-se o papel da mulher ocidental (com enfoque na brasileira) e não-islâmica, considerando que em países que seguem o Alcorão, o acesso de uma mulher a cargos políticos é dificultado, conquanto raramente podem estudar, exceto sob protestos que podem lhe tirar a vida, lembrando o famoso caso da menina Malala ${ }^{3}$. Não se deve ignorar, também, que há algumas exceções nos últimos anos nestes países de maioria islâmica, já que alguns deles foi possível à mulher obter o direito de votar e ser votada, havendo, inclusive, alguns casos em que foram eleitas. No entanto, tratar sobre a conquista de algumas mulheres muçulmanas no mundo islâmico fugirá do tema do artigo, motivo pelo qual o assunto será apenas exposto em certa parte do texto, sem que lhe seja dada maior profundidade acerca do iterpercorrido para que elas obtivessem seus direitos cívicos.

Pois bem, quando se trata de promover algo, entende-se que algo deva ser divulgado, levado a conhecimento, para que the seja dado maior atenção. A comparação vulgar pode se dar mesmo quando se refere à promoção de um produto numa loja, com divulgação na mídia de seu preço reduzido, atraindo consumidores e aumentando, ainda que temporariamente, a demanda daquele produto, seja por necessidade, seja por impulso consumista. Neste sentido, o objeto do trabalho será promover a participação política da mulher, a partir do incentivo que lhe deve ser dado para que concorra a cargos eletivos para diversas esferas administrativas do país, possibilitando, por meio de ações afirmativas, o aumento da ocupação de tais cargos por elas, entendendo-se, por tais ações, medidas tendentes à consecução desta igualdade material, a curto, médio, ou longo prazo, a depender da necessidade para equiparação de situações de direito e de fato.

Será tratado sobre a evolução da mulher como cidadã nos séculos, XIX, XX e XXI, investigando a história e literaturas clássicas que possam ter embasado um tratamento tão discriminatório da mulher por longos períodos. Assim, com o intuito de propiciar às mulheres maior participação efetiva na política será proposto, após análise de alguns países democráticos com eleições regulares, ação discriminatória positiva para possibilitar maior

\footnotetext{
${ }^{3}$ A paquistanesa Malala Yousafzai, de 17 anos, ganhadora do Nobel da Paz de 2014 junto com o indiano Kailash Satyarthi, não conquistou sua notoriedade de maneira fácil. A jovem se tornou conhecida ao mundo após ser baleada na cabeça por talibãs ao sair da escola, quando tinhas (sic) 15 anos. $\mathrm{O}$ ataque aconteceu no dia 9 de outubro de 2012. Malala seguia em um ônibus escolar. Seu crime foi se destacar entre as mulheres e lutar pela educação das meninas e adolescentes no Paquistão - um país dominado pelos talibãs, que são contrários à educação feminina. Fonte: Saiba que é a Malala Yousafzai, a paquistanesa que desafiou os talibãs.
} 
participação feminina nos parlamentos, já que, embora maioria numérica no globo, o gênero feminino, quanto à sua participação política, é minoria, pois materialmente não lhe foi propiciada igualdade de usufruto de seus direitos políticos passivos.

Particularmente em relação ao Brasil, antes de adentrar aos tópicos, convém lembrar que o legislador brasileiro, até o presente momento, pouco tratou de ações afirmativas inclusivas de gênero, pois perante a Constituição Brasileira já existe previsão que vede a discriminação de sexo (arts. $3^{\circ}, \mathrm{IV}, \mathrm{e} 7^{\circ}, \mathrm{XXX}$ ), além do art. $5^{\circ}$, I. No entanto, ao rezar estas normas, tarde se verificou que, ao momento de sua criação, existia a já mencionada desvantagem em relação ao gênero, de maneira que ao longo do período de redemocratização do Brasil, pós 1988, fizeram-se necessárias a edição de algumas leis que pudessem propiciar a igualdade material entre homens e mulheres. Apenas para conhecimento, a mais famosa delas é a Lei Maria da Penha, Lei n. 11.340/2006, que veio para punir com maior rigor a violência doméstica praticada no âmbito familiar contra mulheres, tendo ganhado esta alcunha em homenagem à mulher que por duas vezes quase foi morta pelo marido, ficando paraplégica devida às agressões sofridas. Esta situação a tornou militante no combate à violência contra a mulher. $\mathrm{O}$ tema central do presente artigo é o fomento à participação feminina na política. Pois bem, alguns movimentos de atividades legislativas foram feita em favor das mulheres, dentre os quais as Leis n. 9.100/1995, n. 9.504/1997 (Lei das Eleições) e n. 12.034/2009, com seus termos reproduzidos nas Resoluções de Registro de Candidatura que regulamentam cada Eleição. Recentemente foi proferido parecer na Câmara dos Deputados para a Proposta de Emenda Constitucional (PEC) 134/2015, ou PEC das mulheres, com propósito de minorar discrepância de participantes do sexo feminino na política nos próximos anos.

\section{DIFERENÇA DE GÊNERO NOS SÉCULOS, XIX, XX E XXI}

A mulher dos últimos 150 anos, aproximadamente, tem travado diversas batalhas rumo ao reconhecimento de seu valor igual ao do homem nas mais diversas esferas da vida privada e pública. Ao discorrer sobre o assunto no presente tópico, entender-se-á mulher como pessoa humana do sexo feminino. Será enfatizado o papel da mulher na família e na sociedade, e, para fins deste artigo, com enfoque nas mulheres não islâmicas, considerando que, não obstante a evolução já alcançada pelas mulheres até o presente, as mulheres muçulmanas ainda enfrentam grande dificuldade para sua emancipação, baseada em costumes de países islâmicos e ensinamentos religiosos pertinentes à crença que professam, conforme já citado na introdução.

Assim, apenas em finais dos anos 1800 a mulher começou a lutar para melhoria de sua condição na família e na sociedade, unindo-se a bradar contra o domínio masculino, requerendo melhores condições laborais,

Disponível em: < http://www.todospelaeducacao.org.br/educacao-na-midia/indice/31560/saiba-quem-e-malala-yousafzai-apaquistanesa-que-desafiou-os-talibas/>. Acesso em: 19 jan. 2016. 
direito à educação, à participação política, entre outros.

As raízes da dificuldade da mulher em galgar degraus rumo à sua emancipação, no entanto, ficam muito além dos últimos dois séculos. Talvez Aristóteles, em sua obra Política, do século IV antes de Cristo, seja o precursor de uma suposta ideia de inferioridade feminina. Não obstante considerado um dos maiores (senão o maior) filósofo de todos os séculos, dando inúmeras contribuições para diversas áreas da ciência diante da extrema observação a que se prestava às coisas, viveu em época antiga, e por ser o que observava, transcreveu-o em sua obra, julgando aquilo como certo, pois talvez comportamento unânime da sociedade que se inserira e à época em que viveu. Da mesma forma, foi um defensor da escravidão. Assim, para o filósofo, existia uma constante relação de superioridade da espécie macho para a espécie fêmea, atribuindo-lhe coragem para obedecer aos mandos do sexo masculino, sendo que no homem esta virtude estava em mandar. Mulheres, para ele, eram como metade das pessoas livres (2011, p. 41-44).

A obra de Aristóteles foi por anos ensinada e replicada, sendo de difícil superação até o início das quedas dos Regimes Monárquicos. Ao narrar a defesa da escravidão por Aristóteles, Sandel (2013, p. 247) pontua que, no contexto de cidadania adotado pelo filósofo, consideravam-se mulheres inelegíveis, assinalando que esta exclusão, hoje obviamente uma injustiça, vigorou por mais de 2 mil anos. Foram após alguns movimentos revolucionários, como as revoluções americana e francesa, o advento das repúblicas, que foram trazidos à baila os direitos de primeira geração ou dimensão, sendo o principal o direito à liberdade, e com ele, o movimento liberal, que pedia abstenção do Estado na vida do indivíduo, para que pudesse se autodeterminar, não sendo mais manipulado pelos governos de então. Para a teoria política liberal, os papéis sociais devem ser frutos de escolha, e não de adequação de acordo com sua natureza (SANDEL, 2013, p. 248). Nesta liberdade estava esta novidade do ato de escolha, também por meio de eleições, no que se seguiram, após, direitos de igualdade. Assim, por obra destas comoções sociais, a literatura antiga é revisitada por novos filósofos e estudiosos, que passam a considerar, vez por outra, a participação social de classes outrora marginalizadas, como negros, pessoas pobres, e mulheres, diante da luta social por estas travadas. Em adição a isso, Santos (2013, p. 115) aduz que as novas ordens econômicas surgidas, em especial o capitalismo, acentua a diferença racial e de gênero, dando origem ao sexismo e ao racismo, para os quais corresponderam os movimentos feminista e antirracistas. A isto o sociólogo nomeia reivindicações pósmateriais (2013, p. 130-131), posto que não tangíveis fisicamente.

No Brasil, após a independência, no ano de 1822, começaram articular-se grupos de opiniões, que eram precários e desprovidos de organização para formarem partidos políticos que pudessem, de alguma forma, promover a inclusão feminina, seja social ou política. Em 1889, o Brasil finalmente proclamou sua independência. Não obstante novos tempos instalados, "o avanço inegável que decorreu da instalação da República foi contraposto pela democracia restrita, com escassa participação política”, conforme salientou Pochmann et al. 
(2005, p. 23). De fato, o sufrágio permitido à época foi masculino e censitário, ficando as mulheres excluídas do processo político democrático, o que só veio mudar no primeiro terço do século XX.

Portanto, diante destes vários episódios, a mulher, gradualmente, emancipou-se, fazendo-se incluir social e politicamente. Este movimento, entretanto, ainda está em fase de implementação, pois que não se pode considerar terminado quando ainda existe, não só no Brasil, mas em vários outros países democráticos, grande diferença de participação feminina na política, o que talvez possa ser um dos motivos pela ainda diferente remuneração percebida pelas mulheres em quase todos os países do globo, já que quase não há política para mulheres feita por mulheres.

\section{A EMANCIPAÇÃO FEMININA NA POLÍTICA}

Desde os primórdios, e pode-se dizer que desde a era das cavernas, o papel que coube à mulher foi, quase sempre, o de reprodutora, responsável pelo cuidado dos filhos e tarefas domésticas, não sendo valorizadas, e por inúmeras vezes, sendo maltratadas e até agredidas. Na Antiguidade, poucas mulheres conseguiram ter algum papel de destaque, podendo ser citada a Cleópatra antes de Cristo e Maria, mãe de Jesus, no início da era Cristã, como poucas que tiveram influencia na ordem vigente à época.

Assim, o papel inicialmente atribuído à mulher foi o doméstico, justificado por Aristóteles (2011, p. 57) na necessidade de cuidar dos filhos e dos lares, enquanto ao homem cabia a lida com a terra e a guerra. Ressalta Lopes (2011, p. 224) que:

as mulheres passaram por muitos momentos sombrios, tristes, austeros e opressivos, pois seu contexto de vida era limitado à esfera doméstica, ao cuidado do lar e da família, sendo consideradas inferiores, sem direitos, à mercê dos desejos masculinos e com muitos obstáculos a sua independência.

No mesmo sentido, Thomé e Schwarz (2017, p. 680) pontuam que "the existing gender division of work in our society (...) assigns women the care of family, children and dependents, with the argument that they have a born vocation' for those services." ${ }^{4}$

Nem mesmo os filósofos liberais mostraram interesse em tornar o espaço público mais feminino, já que conforme Kymlicka (2006, p. 325), "a explicação óbvia é que os filósofos homens não tinham interesse em questionar uma divisão sexual do trabalho da qual se beneficiavam”, pois consideravam que os papéis domésticos tinham caráter biológico numa suposta inferioridade da mulher, além do sentimentalismo do gênero que consideravam incompatíveis com a vida política e social.

Não se falava do papel da mulher na esfera pública, posto que poucas vezes do lar se ausentava, devendo obediência ao marido. Diante da já predestinada função doméstica, não lhe era possível aprender outra atividade 
laborativa que não cozinhar, lavar ou costurar, que diga-se, de passagem, até bem pouco tempo eram considerados trabalhos braçais, antes do advento da alta gastronomia, das lavanderias profissionais e ateliês de costura. Ainda, saliente-se que, por longo período, foi considerada relativamente incapaz, devendo obediência ao marido. Assim, caso se rebelasse para laborar fora do lar, corria o risco de vir a divorciar-se, não tendo como se manter. Kymlicka (2006, p. 309) pontua que:

Quando maior parte da "renda familiar" vem do trabalho remunerado do homem, a mulher, que faz o trabalho doméstico não remunerado, torna-se dependente dele para o acesso aos recursos. As consequêencias desta dependência tornaram-se mais evidentes com o aumento da taxa de divórcios. Enquanto os casais casados podem compartilhar o mesmo padrão de vida durante o casamento, independente de quem receba a renda, os efeitos dos divórcios são catastroficamente desiguais.

No Brasil, esta relação de subordinação da mulher ao homem foi positivada pelo Código Civil de 1916, que tratava a mulher casada como relativamente incapaz, podendo exercer atividade fora do lar, entre outros atos listados pelo referido diploma legal, apenas se autorizada pelo esposo. Dispunha o artigo 6 ${ }^{\circ}$. do Código Civil, (Lei n. 3.017, de $1^{\circ}$ de janeiro de 1916), em seu inciso II, serem incapazes, relativamente a certos atos, ou à maneira de os exercer, as mulheres casadas, enquanto subsistisse a sociedade conjugal. No artigo $2^{\circ}$ daquele Código, ao mencionar que todo "homem" era capaz de direitos e obrigações na ordem civil, referia-se realmente apenas ao sexo masculino, e não homem como espécie humana. Tal situação só se atenuou no ano de 1962, com o Estatuto da Mulher Casada, Lei n. 4.121, de 27 de agosto daquele ano, que retirou a mulher casada do rol de relativamente incapazes, embora ainda continuasse a lhe impor alguns ônus decorrentes do casamento. Não obstante o advento da Constituição de 1988 e o Novo Código Civil de 2002, lei n. 10.406, de 10 de janeiro daquele ano, terem extirpado essa distinção, os efeitos psicológicos desta "autorização marital" ainda podem ser vistos em alguns casamentos, não sendo raro que as mulheres trabalhem meio período para cuidar também da casa e dos filhos, ou optem por permanecer em casa, diante da discriminação remuneratória e oportunidades inferiores de trabalho, muitas vezes assim denominadas apenas por serem exercidas por elas. Afinal, a mulher que cozinha é cozinheira. $\mathrm{O}$ homem, chef de cozinha! A que costura, costureira. O que costura, alfaiate ou estilista!

Retomando o percurso emancipatório, a mulher, para sair do ambiente doméstico, e diante de suas habilidades com algumas atividades que the eram julgadas naturais e pertinentes à época, como a costura, passou a trabalhar como operária, inicialmente em tecelagens. Eram, no entanto, muito mal remuneradas, vindo a se unir e reivindicar melhores condições de trabalho. Após lutas sangrentas, como já dito, a mulher conseguiu quebrar a barreira do privado, mostrando que poderia exercer atividade que não apenas aquela pertinente ao lar.

Eram, no entanto, alijadas, na maioria dos países, do direito ao voto e da educação, não tendo cidadania plena. Não thes era dado ou era dificultado o estudo, sendo poucas as mulheres que possuíam títulos científicos e

\footnotetext{
${ }^{4}$ A existente divisão de trabalho por gênero na nossa sociedade $(\ldots)$ atribui a mulheres os cuidados com a família, filhos e
} vol.10, no. 04, Rio de Janeiro, 2017.pp. 29042925 
o direito à participação cidadã. As lutas mais intensas, de acordo com a redação de Pinto (2010, p. 15), iniciaramse na terra da monarquia inglesa, onde

A chamada primeira onda do feminismo aconteceu a partir das últimas décadas do século $\mathrm{XIX}$, quando as mulheres, primeiro na Inglaterra, organizaram-se para lutar por seus direitos, sendo que o primeiro deles que se popularizou foi o direito ao voto. As sufragetes, como ficaram conhecidas, promoveram grandes manifestações em Londres, foram presas várias vezes, fizeram greves de fome. Em 1913, na famosa corrida de cavalo em Derby, a feminista Emily Davison atirou-se à frente do cavalo do Rei, morrendo. O direito ao voto foi conquistado no Reino Unido em 1918.

Com efeito, cidadania, em sentido estrito, no direito brasileiro, compreende a titularidade individual dos direitos políticos de votar e ser votado e sua consequências, sendo adquirida a partir do alistamento eleitoral, conforme ensina Silva (2015, p. 350). Logo, no Brasil só é cidadão o eleitor, acrescentando-se o fato de que deve estar em dia com suas obrigações para a Justiça Eleitoral, ou seja, quite, para utilizar expressão técnica pertinente.

Diante desta condição peculiar para ser cidadão em sentido estrito, diante de informações obtidas em sítio do governo, Portal Brasil, em terras nacionais

A luta das mulheres pelo espaço na política é antiga. Ainda no período do Império, em 1880, a dentista Isabel de Mattos Dillon evocou na Justiça a Lei Saraiva (que permitia aos detentores de títulos científicos votar) para requerer seu alistamento eleitoral.

Nos anos seguintes, surgiram várias iniciativas isoladas para permitir o voto feminino. Em 1894, Santos, no litoral paulista, promulga o direito das mulheres ao voto. A medida foi derrubada no ano seguinte. Em 1905, três mulheres conseguiram se alistar e votar em Minas Gerais.

Em 1928, o Brasil elege sua primeira prefeita: Alzira Soriano de Souza, na cidade Lages, no Rio Grande do Norte. O voto feminino só se tronou um direito nacional em 1932.

Coletivamente, Pinto (2010, p. 16) aponta que o primeiro movimento feminista no Brasil, cujo cabeça era a bióloga e cientista Bertha Lutz, organizava-se publicamente a favor do voto feminino, tendo sido, inclusive, encaminhado abaixo-assinado ao Senado que pedia aprovação do projeto de lei que dava às mulheres o direito ao voto, o que só veio a se concretizar com a promulgação do Código Eleitoral de 1932. Lérias (2008, p. 220-221), aponta que este diploma legal ampliou consideravelmente o número de eleitores, e atribui a conquista do voto feminino a partir da determinação do voto secreto, o que, não obstante tenha ou não sido a intenção do legislador à época, "representou um avanço substancial nos direitos políticos brasileiros, se se pensar que o Brasil foi o segundo a fazê-lo na América Latina."

Em termos globais, ainda sobre a luta pelos direitos políticos, resume-se sem seguida, temporalmente, a luta pelos direitos políticos a favor das mulheres, considerando países mais influentes no cenário mundial. Assim, tem-se início o movimento sufragista feminino em alguns estados isolados nos Estados Unidos, entre 1848 e 1896. Foi, no entanto, a Nova Zelândia, no ano de 1893, o primeiro país do mundo a conceder o sufrágio feminimo, sendo que na esfera municipal, naquele país, elas já detinham estes direitos desde o ano de 1886. A 
Austrália deu direitos políticos às mulheres no ano de 1901. Paralelamente a isso, a Europa se articula para dar às mulheres o direito de voto, sendo John Stuart Mill quem apresentou ao Parlamento inglês proposta de emenda que dava às inglesas o direito de votar, no ano de 1866, não obstante nacionalmente as mulheres só tenham ido às urnas no ano de 1918. Foram, no entanto, primeiramente os países nórdicos a conceder o sufrágio feminino. O voto feminino foi progressivo, e não foram os países mais influentes os pioneiros: Espanha permitiu o voto das mulheres em 1931. França, berço da Revolução Francesa, e Itália, apenas após a Segunda Guerra Mundial. Suíça, a derradeira nação a reconhecer este direito fundamental às mulheres, no ano de 1971. Na América Latina foi pioneiro o Equador, em 1929, sendo o Brasil o segundo país a admitir o sufrágio feminino, como já assinalado. A Argentina apenas em 1947 pode ter o voto feminino, a partir da militância de Eva Perón, primeira dama na ocasião.

Seguiram os demais países, gradualmente, a atribuir direitos políticos às mulheres, não cabendo aqui, no entanto, nomeá-los exaustivamente.

Por derradeiro, o último país do mundo a conceder direitos políticos às mulheres foi a Arábia Saudita, que apenas em 12 de dezembro de 2015 realizou o primeiro pleito em que mulheres puderam votar, e supreendentemente, ser também votadas, tendo concorrido 900 mulheres e 6 mil homens, conforme notícia jornalística daquela data, no sítio do gl.globo.com..

Assim, após narrar, em linhas gerais, o caminho percorrido pelo mulher até obtenção do voto, segue, no próximo tópico, análise da participação política da mulher em sua plenitude, não apenas como receptora das políticas governamentais, mas como protagonistas, legisladoras e administradoras no poder público, podendo ser votadas e efetivamente eleitas em eleições regulares.

\section{A PARTICIPAÇÃO DA MULHER NA POLÍTICA COMO PROTAGONISTA}

Conforme visto, data dos fins dos anos de 1800 a inclusão gradual, não obstante lenta, das mulheres na participação democrática. Após ter adquirido o direito ao voto em grande parte dos países democráticos, algumas mulheres passaram, também, a reivindicar o direito de serem votadas, isto é, de usufruir também de direitos políticos passivos. Com efeito, Gomes (2015, p.153) definiu direitos políticos ou cívicos como "a capacidade de votar e ser votado, significando a prerrogativa de participar direta ou indiretamente do governo, da organização e do funcionamento do estado." Assim, o direito ao voto, de ir às urnas é o direito político ativo, e o direito de receber o voto de si e de outros eleitores, direito político passivo.

Era, de início, difícil a saída da mulher para o espaço público conquanto sociologicamente predestinada a ser esposa e mãe, não obstante infeliz, o que ficou retratado, inclusive, em diversos romances da literatura mundial, com certo destaque para "A mulher de 30", de Honoré de Balzac, no qual a pobre Julia, protagonista do romance, 
embora não suportasse o casamento e seu marido, lhe era servil e obediente.

Mesmo grande pensadores e filósofos não reconheciam, na mulher, uma pessoa cidadã. Spinoza (2013, p. 144 e 145) justificava que:

...veremos que a exclusão das mulheres é uma conseqüência de sua fraqueza. Com efeito, não se viu, em parte nenhuma, dominar, conjuntamente, os homens e as mulheres. Ao contrário, por toda parte em que se encontram homens e mulheres, as mulheres são governadas e os homens governam, e deste modo, a concórdia existe entre os dois sexos.(...) Ora, se fosse natural que as mulheres se igualassem aos homens em com eles pudessem rivalizar tanto pela grandeza da alma, como pela inteligência, e é o que constitui, principalmente, o poder do homem e, de conseguinte, o seu direito, certo, entre tantas noções diferentes, ver-se-iam algumas onde os dois sexos governassem do mesmo modo, e outros em que os homens seriam governados por mulheres e educados de maneira a ser menos fortes pela inteligência. Como tal coisa não acontece em nenhuma parte, pode-se afirmar, sem restrição, que a natureza não deu às mulheres um direito igual ao dos homens, e que são obrigadas a reconhecer-lhes a superioridade. Logo, não se pode concluir que os dois sexos governem igualmente, e, ainda menos, que os homens sejam governados pelas mulheres.

Para a mudança deste papel, contribuiu notoriamente a figura de Simone Lucie-Ernestine-Marie-

Bertrand de Beauvoir, conhecida mundialmente apenas como Simone de Beauvoir, mulher francesa estudada na famosa Universidade de Sorbonne, que pregava a transcendentalização da mulher, do feminino, a partir da teoria existencialista de Jean Paul Sartre, seu companheiro intelectual e com quem teve longa relação pessoal, embora jamais tenham se casado. Essa transcendentalização consistia em procurar resposta para o que é uma mulher, a partir do existencialismo, cujo mote é a descoberta de si através da liberdade de escolha numa dada sociedade.

Desta maneira, encorajadas a superar suas limitações, e diante de novas ondas feministas, nos anos 60 e 70, um grupo de mulheres passou a reivindicar melhores condições de vida, de trabalho, mediante remuneração justa, de participação política. Pinto (2010, p. 16) ensina que:

O feminismo aparece um movimento libertário, que não quer só espaço para a mulher - no trabalho, na vida pública, na educação -, mas que luta, sim, por uma nova forma de relacionamento entre homens e mulheres em que esta última tenha liberdade e autonomia para decidir sobre sua vida e seu corpo. Aponta, e isto é o que há de mais original no movimento, que existe uma outra forma de dominação - além da clássica dominação de classe -,dominação do homem sobre a mulher - e que uma não pode ser representada pela outra, já que cada uma tem suas característica próprias.

Neste sentido, é que algumas mulheres começam a se lançar na política, saindo candidatas a cargos eletivos tanto dos Poderes Legislativo quanto Executivo, buscando representar as mulheres e seus interesses, embora, no Brasil, mesmo antes de tais ondas feministas algumas candidatas já tinham sucesso em ser eleitas. Pinto (2014, p. 566) mostra que foi Suely de Oliveira a primeira mulher eleita como deputada estadual, pelo Partido Trabalhista Brasileiro (PTB), tendo se reelegido cinco vezes, ocupando cadeira na Assembleia Legislativa do Rio Grande do Sul no período entre 1950 e 1974. Esta conquista tenha sido obtida antes que alguns países democráticos concedessem votos às mulheres, até os dias atuais não houve crescimento significativo no número de mulheres eleitas, não apenas no país, como em outras democracias, o que tem sido objeto de estudo de gênero 
e reivindicação da militância feminina. A citada autora, neste estudo referenciado, tratou da história da deputada eleita, e a descreveu no título de seu artigo como uma mulher "recatada".

Interpretando este título, e de acordo com o que se depreende do texto em questão, fica claro que Suely tenha sido uma mulher a frente de seu tempo, precisou manter certo "recato" dentro da Assembleia Legislativa pois vivia num ambiente predominantemente masculino. Seja talvez, esse, uma das razões desmotivadoras para que as mulheres não se lancem na política, não obstante, nos dias de hoje, ao menos no Brasil, haja lei de cotas que obriga que os partidos políticos reservem vagas para o gênero feminino para fins de concorrência eleitoral.

\section{Ações afirmativas para inclusão feminina nos cargos eletivos}

Quando se está diante de uma situação de desigualdade real, gerada por contextos sociais ou jurídicos, Estados que se dizem sociais tem lançado mão de ações afirmativas para equiparação fática de condições entre sua população.

Ferreira Filho (2012, p. 141), sobre ações afirmativas, ensina:

É necessário distinguir das discriminações, que violam o princípio da igualdade, as "ações afirmativas", que podem ser com elas compatíveis.

Essas ações afirmativas tiveram origem nos Estados Unidos da América e hoje se difundiram pelo mundo, estando presentes no Brasil atual. São elas distinções no sistema normativo, em benefício de grupos determinados - negros, mulheres, etc. - que visam a equipará-los (igualálos) a grupos outros que servem de padrão de referência. (Na prática, os negros aos brancos, as mulheres aos homens etc.)

Justificam-se tais distinções pela finalidade que é igualar e não desigualar, mas igualar corrigindo tratamentos discriminatórios - portanto, prejudiciais ao grupo - globalmente vigorantes na sociedade. Refletem elas a ideia do tratamento desigual dos que se apresentam desigualados na sociedade. Levam em conta não os indivíduos isoladamente considerados, mas os grupos a que pertencem.

Ainda, reforça Belintani (2006, p. 47) que:

Atualmente, as ações afirmativas são definidas como mecanismos legais temporários, que têm por escopo fomentar a igualdade substancial entre os membros da comunidade que foram socialmente preteridos, valendo-se, para tanto, da possibilidade de inserir discriminações positivas, no sentido de tratar desigualmente os desiguais, para que estes possam alcançar o mesmo nível, patamar ou status social que os demais membros da comunidade.

Neste sentido, algumas ações afirmativas foram se firmando no sentido de promover a inclusão das mulheres na política, como candidatas. Foi a partir da Lei n. 9.100/1995 que mulheres passaram a ter direito a ocupar 20\% das vagas destinadas à candidatura eleitoral por um partido ou coligação, tendo esse percentual aumentado para 30\% com o advento da Lei das Eleições, Lei n. 9.504/1997. Com esta reserva de vaga para candidatura, não houve aumento considerável de mulheres eleitas, considerando que, em verdade, não havia obrigatoriedade para preenchimento destas vagas, podendo o partido ou coligação deixá-las vazias, motivo que fez o Tribunal Superior Eleitoral (TSE), no ano de 2010, a partir da interpretação de outra lei de cunho 
discriminatório positivo, Lei n. 12.034/2009, tornar obrigatória a participação das mulheres, interpretando a lei pelo viés da compulsoriedade do preenchimento de tais vagas. Diante disto, verifica-se partidos colocando algumas mulheres nesta vaga apenas para "mostrar" que cumprem a lei a medida do possível, incentivando a candidatura feminina, não sendo raro casos em que muitas obtém apenas o voto de seus familiares, pois não contam com o apoio do partido para suas campanhas, ou mesmo figurem no resultado final sem voto alguém. No entanto, não se prevê punição caso haja o descumprimento desta porcentagem, e na prática, a ação afirmativa não surtiu efeitos. $\mathrm{O}$ aferimento do número de mulheres é feito quando do registro de candidaturas, não sendo raro renúncias e mulheres sem voto algum após passado o período para impugnação ao registro. Eis a burla à lei, passível, no entanto, de ação de investigação judicial eleitoral proposta pelo Ministério Público para apuração de fraude, o que, no entanto, não se mostrou frequente no pleito do ano de 2016.

No texto Mulheres na Política, o Professor José Eustáquio Diniz Alves, da Escola Nacional de Ciências Estatísticas do IBGE, se referindo à pouca participação das mulheres na política relata que "o fenômeno não decorre da carência de mulheres aptas a concorrer, mas antes do modo os partidos são organizados: 'Eles são controlados por homens, que dão pouco espaço para as mulheres estruturarem suas campanhas."

Com efeito, não apenas no Brasil a questão do exercício dos direitos políticos passivos da mulher só foi recentemente colocada em discussão. Apenas para comparar ao país berço da democracia moderna, a França, no ano de 1982, o Conselho Constitucional censurou uma lei que previa uma quota de $25 \%$ para participação feminina em eleições municipais com base no princípio da igualdade (formal), o que gerou um obstáculo para uma igualdade real de representação entre homens e mulheres. O tema só voltou a surgir quando das eleições presidenciais de 1995, quando Jacques Chirac, então presidente daquele país, se comprometeu a tomar medidas para resolver a paridade. Nos anos seguintes foram instituídas cotas para eleição, sob pena de multa ao partido que não contemplasse mulheres entre suas candidatas, tendo a legislação se aperfeiçoado até o ano de 2007.

No entanto, em França, ao contrário do Brasil, talvez pela sanção financeira aos partidos que não incluíssem mulheres na política, o aumento no número das mulheres que ocupam cadeiras eletivas teve sensível aumento, o que faz crer que, realmente, há necessidade de políticas públicas por meio de ações afirmativas para a inclusão feminina e sua emancipação política.

Sobbottka (2009, p. 157), questiona:

Pode-se perguntar, por que políticas sociais deveriam se um direito dos cidadãos? Döring (2004) defende que é para "evitar formas extremas de desigualdade e, com isso, assegurar a coesão interna da sociedade". Já Goodin et al. (2002) mencionam seis razões para a existência de políticas sociais: apoiar eficiência econômica, minimizar a pobreza, fomentar a integração e evitar a exclusão social, assegurar estabilidade, fomentar a igualdade social e proteger a autonomia individual. Estas razóes pode sem agrupadas como econômicas (estabilizar a conjuntura, incrementar a produção de bem-estar), políticas ou funcionais (integrar os distintos grupos sociais, ampliar lealdade e legitimidade) e normativas ou éticas 
(justificar intervenção do Estado na vida do cidadão).

Diante da última citação, vê-se, portanto, que incrementar a participação das mulheres na política não é apenas uma conquista dos movimentos femininos, mas um dever do Estado, pautado nas evidências listadas acima.

Mas não se estaria, desta maneira, mostrando uma incapacidade feminina em não ter o dom da política? A resposta é negativa: crer que uma mulher não possa ter autonomia e poder de decisão é retornar a Aristóteles, Spinoza, entre outros filósofos, mesmo de tempos não tão antigos. O que se propõe, com a Lei de Cotas e outras que fomentam a participação feminina é quebrar a barreira de um ambiente outrora predominantemente masculino, encorajando mulheres a expor suas propostas e ideias, por séculos sufocadas no ambiente doméstico. Trata-se de uma medida do Estado mostrando que enxerga a mulher, permite e até exige sua participação na formação política e democrática do Estado, para deixá-la mais confortável para expor em ambiente antes inóspito a seu gênero, conforme já exposto acima quando se falou da deputada gaúcha Suely de Oliveira.

\section{Política para os iguais - promoção da igualdade material}

Mas por que fomentar a eleição de mulheres, pois se na maioria das nações não islâmicas, mulheres tem os mesmos direitos que os homens, não havendo distinções perante a lei?

Porque existe uma distorção histórica no papel social, político e econômico das mulheres, que ainda as faz vulneráveis, não havendo políticas que garantam materialmente uma igualdade de oportunidades, não obstante papéis destinados a homens e mulheres tenham sido questionados e reexaminados, provocando alterações na participação política, conforme pontuam Bertoncini e Padilha (2017, p. 311-312). Muitas já foram as conquistas pelas mulheres, como licença maternidade, proibição de testes de gravidez antes de contratação, e até mesmo permitir a entrada de mulheres trajando calças compridas em altos órgãos públicos do Poder Judiciário ${ }^{5}$. Mesmo com a permissão, concedida no ano 2000 para o Supremo Tribunal Federal (STF), a mais alta Corte Judiciária brasileira, foi apenas no ano de 2007 que a primeira mulher entrou trajando calças compridas, isto desde a criação da Corte, em 1928, conforme noticiado em 15 de março de 2007 pelo sítio eletrônico

\footnotetext{
${ }^{5}$ No Brasil, até maio do ano 2000 mulheres não podiam frequentar as dependências do Supremo Tribunal Federal (STF), a mais alta Corte de Justiça do país, trajando calças. Noticia o sítio do STF que "A tradição da exigência do uso de saias ou vestidos no vestuário feminino durou vários anos, mas em uma quarta-feira, dia 3 de maio de 2000, essa regra caiu. Em sessão administrativa, os ministros do Supremo Tribunal Federal permitiram o uso de calça comprida pelas mulheres, desde que acompanhada de blazer.

A mudança já vislumbrava um novo tempo na Corte e a preparava, de certa forma, para receber a primeira mulher a se tornar ministra do Supremo. Em 23 de novembro daquele ano, o então presidente da República, Fernando Henrique Cardoso, nomeou a magistrada carioca Ellen Gracie Northfleet para uma vaga no STF." Embora se trate de Poder Judiciário, cujo ingresso, no Brasil, é via de regra, por meio de concurso público de provas e títulos, quando se trata de integrar a Suprema Corte, há uma escolha político eletiva entre operadores de diferentes áreas do Direito, de maneira que não destoa do presente artigo citar o fato como uma conquista emancipatória das mulheres de cunho político. Fonte: Ellen Grace, a trajetória de uma década da primeira mulher a
} 
g1.globo.com, em texto intitulado: "Ministra veste calça em plenário do STF e quebra tabu".

Assim, foi apenas com a entrada de mulheres na Corte Suprema Brasileira que algumas normas de cunho altamente sexista começaram a se conformar com a autonomia e emancipação da mulher. Num ambiente predominantemente masculino, como o STF, mesmo com permissão para entrada de calças, foram sete anos para que uma mulher, a Ministra Carmen Lúcia Antunes Rocha, efetivamente entrasse trajando calças compridas na Corte.

Trata-se de um exemplo isolado, mas pensando macro, muitas mulheres tolhem seus anseios por mais liberdade, receiam reivindicar direitos garantidos na Constituição por se sentirem, ainda, psicologicamente oprimidas. Assim, em havendo o fomento à sua participação na política e efetiva eleição, embora ainda se esteja a um longo caminho de superar a maioria e alcançar números próximos de participação, isto diminuirá a vulnerabilidade e invisibilidade sofrida pelo gênero feminino.

Com efeito, explica Alves (2013, p. 127):

O que caracteriza a vulnerabilidade, da qual decorre a exclusão, é a invisibilidade, eles (os excluídos - grupos minoritários ou vulneráveis) não são levados em conta pelo conjunto da sociedade, ou pelos atores sociais dominantes (entre os quais o mercado) para a formulação de agendas públicas.

Assim, há que se destacar que desde a redemocratização do Brasil no ano de 1988, as poucas mulheres que estão engajadas na política lutam para diminuir esta dita invisibilidade, já que, conforme escreve Amâncio (2013,p. 75)

a política se constitui como um campo estratégico de atuação, uma vez que, através dos projetos gestados e forjados em seu âmbito, são continuamente criadas e recriadas várias formas de luta e resiste ncias sociais. De acordo com esta perspectiva, a ascensão das questões femininas no meio público proporcionou maior visibilidade para as mulheres e para os movimentos engendrados por elas. Assim, a politização das questões femininas permitiu "um olhar mais de perto" acerca do processo de redemocratização da sociedade, bem como uma participação mais efetiva no debate Constituinte e na elaboração da nova Carta Magna.

Com efeito, Cabra (2017,p. 854) assinala que "é num contexto complexo e pluralista que a dimensão do público se desenvolve como um meio discursivo de articulação de demandas e de solução de problemas".

"Lobby do Batom" foi o nome dado à participação política feminina durante a elaboração da Constituição de 1988. Em monografia, Vaz (2008, p. 34-35) expõe que:

Feministas e grupos de mulheres exerceram pressa o constante, atrave冈s de uma aça o direta de convencimento dos constituintes, que a imprensa identificou como o "lobby do batom". Dessa forma, praticamente $80 \%$ de suas reivindicaço es foram atendidas, como por

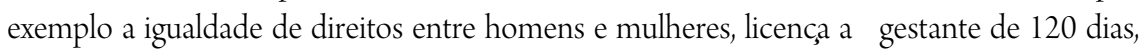
entre outras. A bancada feminina atuou como um verdadeiro "bloco de ge nero", atuou independentemente de filiaça o partida邓ria, superando diverge ncias ideolo®gicas. Elas

integrar o STF. 08 ago 2011. Disponível em: http://www.stf.jus.br/portal/cms/verNoticiaDetalhe.asp?idConteudo=185964 . Acesso em: 28 jan 2016. 
apresentaram, em bloco suprapartida®rio, a maioria das propostas, garantido a aprovaça o das demandas do movimento.

Diante de tais exposições, vê-se que a discriminação reversa fomentou a participação feminina na política, não atingindo, no entanto, níveis satisfatórios de mulheres eleitas, sendo pequena a porcentagem de cadeiras ocupadas por mulheres nos Poderes Legislativo e Executivo. Com efeito, até o presente momento, houve um incentivo à reserva de vagas para candidatura, não à reserva de assentos. Comparativamente falando, utilizando as cotas universitárias como exemplo, seria exigir porcentagem de concorrentes negros, sem que no entanto eles tivessem chances reais de obter um lugar na sala de aula de uma universidade.

Assim, fala-se em reserva de assento parlamentar para mulheres, assunto que é tratado na PEC das Mulheres, a qual no próximo tópico será analisada, pois se depreende que países adeptos de tal política inclusiva estão obtendo a paridade de gênero na política, como a Ruanda, que figura no topo do ranking mundial como o país que mais mulheres participam dos poderes executivo e legislativo, ao passo que o Brasil, com base nas últimas eleições, datadas de 2014, figura na $158^{a}$ posição, com apenas $9 \%$ de mulheres eleitas, quando tomado por base o órgão mais numeroso em termos de representação, a Câmara dos Deputados, conforme a $2^{a}$. Edição do Livreto Mais Mulheres Na Política (2015, p. 52-57).

\section{Cotas para eleição, não para candidatura}

Destarte, a experiência das últimas décadas no sentido de promover a inserção da mulher nos parlamentos não alcançou a paridade almejada pelos defensores da cidadania e igualdade. Por quase toda a antiguidade, modernidade e era contemporânea sendo os Estados e suas unidades governados por homens, entenda-se, indivíduos do sexo masculino, tornou-se difícil, à mulher, adentrar no meio político, considerando, ainda, que por muito tempo foram privadas de direitos fundamentais, como a igualdade, comprometendo até a cidadania.

Alves (2008, p. 281-282) escreve:

A cidadania é o direito a ter direitos. A cidadania só é plena na medida em que os direitos fundamentais são assegurados, sendo que o principal deles é o direito à diferença. Esse asseguramento é, na verdade, uma conquista dos sujeitos historicamente privados de direitos fundamentais por serem diferente de quem detém o poder e controla a macro-política. A afirmação das diferenças históricas daqueles que estão no centro e na margem do processo de construção do Estado brasileiro, e a conquista de uma tutela não alienante dessa diferença são capazes de construir uma isonomia real, ou seja, uma igualdade substancial e não apenas aquela, formal, perante a lei.

Para tanto, mesmo com políticas inclusivas que oportunizem a concorrência nas eleições, tornam-se necessárias medidas que garantam uma vaga nos poderes legislativos, compostos por vários membros, de maneira a amenizar a distorção no quadro de representação popular democrática. Dessa forma, além da já existente reserva de vagas para mulheres nas listas dos partidos referente aos candidatos aptos a concorrer, urge que seja adotada a 
política de reserva de assento, isto é, reserva de cadeiras nas casas legislativas, de maneira que uma porcentagem de mulheres pudessem ser eleitas sem que fosse atingida a quantidade mínima de votos necessária, para assim se encaixar entre as cadeiras regulares, pois sua vaga estaria reservada. Dessa forma, além das vagas preenchidas pelo processo eleitoral ordinário, uma quantidade específica, de acordo com o número de assentos, viria a ser preenchida pela(s) mulher(es) com mais votos dentre os partidos que obtivessem o quociente partidário ${ }^{6}$, decrescentemente, mesmo que essas mulheres não tivessem atingido o mínimo de votos exigido pelo sistema eleitoral ${ }^{7}$, o que só não é compatível com o sistema distrital.

Assim, exemplificando, uma casa legislativa com dez vagas reservará 20\% de seus assentos, ou seja duas vagas, para mulheres, mesmo que não tenham atingido o mínimo de votação para que pudessem figurar entre as oito vagas. Assim, numa eleição com partidos A, B, C e D, apenas A, B e D alcançaram o quociente partidário. Na distribuição das cadeiras, serão consideradas oito vagas, e não dez. As duas vagas remanescentes seriam ocupadas por mulheres dos partidos $\mathrm{A}, \mathrm{B}$ ou $\mathrm{D}$, mais votadas, em ordem decrescente, para ocupar a nona e a décima vaga, ainda que na lista figurassem, em suas frentes, homens com mais votos.

De fato, países com reserva de assento de gênero têm logrado êxito na consecução da paridade de gênero representativa, como o já citado exemplo da Ruanda. Por tais razões, no Brasil, a bancada feminina do Senado Federal propôs o Projeto de Emenda Constitucional (PEC) das Mulheres, 98/2015, que prevê reserva de assentos progressiva para os próximos pleitos, a fim de sanar a disparidade existente entre homens e mulheres no Poder Legislativo. A proposta seria acrescentar o artigo 101 ao Ato das Disposições Constitucionais Transitórias, moldes aproximados do exemplo exposto acima. Assim, ler-se-ia, na Carta Magna, o seguinte excerto:

Art. 101. É assegurado a cada gênero percentual mínimo de representação nas cadeiras da Câmara dos Deputados, Assembleias Legislativas, Câmara Legislativa do Distrito Federal e Câmaras Municipais, nas três legislaturas subsequentes à promulgação desta Emenda Constitucional, nos termos da lei, vedado patamar inferior a:

I - $10 \%$ das cadeiras na primeira legislatura;

\footnotetext{
${ }^{6}$ Quociente partidário é o mínimo de votos necessário que o partido ou coligação necessita para obter uma vaga em casas legislativas. Considerando que o assento pertence ao partido, e não indivíduo, reservar o assento de gênero para uma mulher mais votada, mas que seu partido, no entanto, não tivesse obtido o quociente partidário, seria corrigir uma falta com um erro, pois certamente, muitos partidos que dificilmente tivessem oportunidade de atingir este mínimo de votos para ter direito a uma vaga, lançariam mão de candidatas famosas, sub-celebridades, capazes de angariar mais votos que mulheres realmente engajadas na causa política.

${ }^{7}$ Sistemas Eleitorais: Quatro são os sistemas eleitorais conhecidos: Majoritário, Proporcional, Distrital e Misto. Por questões didáticas, a seguir será dada breve explanação acerca dos três primeiros, considerando que suficiente para entendimento do presente artigo. Majoritário: é eleito o candidato que receber a maioria dos votos nominalmente, seja ela absoluta ou relativa. Proporcional: visando representar diferentes pensamentos e tendências de uma dada sociedade, possibilita o voto nominal no candidato, ou apenas no partido, de maneira que o partido que obtiver maior número de votos poderá ver os assentos ocupados por seus candidatos, ainda que apenas o primeiro tenha tido votação expressiva, sendo que os demais, mesmo com votação nominal inferior a candidatos de um outro partido que obteve, no total menos votos, poderão assumir uma vaga, ao passo que candidato com votação nominal maior, mas com partido com votação inferior, poderá não ser eleito. Este sistema aplica-se na maioria dos países para eleiçōes ao Poder Legislativo. Distrital: cada partido pode lançar apenas um candidato por distrito/região, sendo eleito o que obtiver mais votos, nominalmente, a exemplo dos Estados Unidos da América.
} 
II - $12 \%$ das cadeiras na segunda legislatura;

III - $16 \%$ das cadeiras na terceira legislatura.

$\$ 1^{\circ}$ Caso o percentual mínimo de que trata o caput não seja atingido por um determinado gênero, as vagas necessárias serão preenchidas pelos candidatos desse gênero com a maior votação nominal individual dentre os partidos que atingiram o quociente eleitoral.

$\S 2^{\circ}$ A operacionalização da regra prevista no $\$ 1^{\circ}$ dar-se-á, a cada vaga, dentro de cada partido, com a substituição do último candidato do gênero que atingiu o percentual mínimo previsto no caput, pelo candidato mais votado do gênero que não atingiu o referido percentual.

\30 Serão considerados suplentes os candidatos não eleitos do mesmo gênero dentro da mesma legenda, obedecida a ordem decrescente de votação nominal.

Do exposto, depreende-se que a reserva de assento somente ocorrerá se candidatos de determinado gênero não atingirem o mínimo de ocupação nos assentos, não havendo reserva de assentos necessária caso a percentagem seja atingida regularmente, sendo a proposta da emenda, até mesmo, menos inclusiva que o exemplo dado acima, o que não a poupou de críticas, conforme será visto em breve.

Com efeito, em relatório parcial, o senador Romero Jucá consignou que:

Identificado o problema, e cientes de que a sub-representação feminina é um problema a ser enfrentado pela democracia brasileira, propomos a adoção de ação afirmativa, que se apresenta na forma de reserva de um percentual mínimo de cadeira nas representações legislativas em todos os níveis federativos.

Nossa proposta começa com um patamar mínimo de 10\%, que se eleva gradualmente até alcançar, pelo menos, os $16 \%$.

Ressalte-se que a ação afirmativa tem prazo definido. Entendemos que, uma vez garantida a representação, as barreiras socioculturais enfrentadas pelas mulheres serão mitigadas a tal ponto que, a partir da quarta legislatura subsequente à promulgação desta Emenda Constitucional, não se fará mais necessário consignar na legislação um nível mínimo de representação.

Encerrada a tramitação no Senado Federal, em meados de 2015, a PEC entrou em trâmite na Câmara dos Deputados, com o número 134/2015. O assunto, no entanto, não é de todo novo, pois consultando os trâmites nas Casas Legislativas Nacionais, nota-se que foram apensadas à PEC 134/2015 as PECs 205/2007 e 371/2013, também com tentativas de incluir reservas de assento.

Inicialmente houve admissibilidade a proposta pela Relatora Deputada Federal Soraya Santos, mas em voto separado, já na Comissão de Constituição e Justiça e de Cidadania, o deputado federal Evandro Gussi votou pela inadmissibilidade da PEC, apontando motivos, dos quais cumpre consignar afronta ao valor do voto direto e igual:

Da previs@̀ constitucional estabelecida no Art. 14, caput, da CF/88, decorre a clara compreensa o que o voto direto $\mathrm{e} \boldsymbol{\nabla}$ o voto de um cidada o em um representante, configurando clara afronta ao regramento ali estabelecido a proposta objeto da presente PEC 134, de 105, pois trara $\triangle$ como resultado que o voto dado a um determinado candidato terminara $\bigotimes$ valendo mais que o voto dado a outro, em tudo contra冈rio ao princi®pio do voto igualita冈rio.

Na o se pode admitir, portanto, que um voto dado por uma pessoa, por suas condiço es pessoais, valha mais que o dado por qualquer outra pessoa, sejam quais forem, tambe $\ \mathrm{~m}$, as suas condiço es e convicço es pro®prias. 
Considera ele, ainda, que a proposta é uma abolição ao princípio da igualdade exposto na Constituição, e sua admissibilidade poderá ferir cláusula pétrea:

De se destacar, ainda, que a inovaça o constitucional ora pretendida configura clara contrariedade $a \rrbracket$ pro®pria igualdade entre homens e mulheres em seus direitos e obrigaço es, na forma prevista no Art. 5o, inciso I, da Constituiça o Federal. Nesse ponto, a presente emenda pretende abolir um Direito Fundamental, o que $\mathrm{e} \mathbb{\nabla}$ vedado pelo art. 60, $₫ 40$, IV.

Após esta manifestação, com data no sítio eletrônico da Câmara dos Deputados de 18 de novembro de 2015, o projeto voltou a ser debatido na Comissão de Constituição e Justiça em meados de 2016, sendo aprovado o parecer com votos contrários de oito deputados do sexo masculino. Foi publicado o parecer no mês de novembro de 2016, sem que, no entanto, até o presente, tenha sido incluído qualquer artigo na CF que verse sobre o assunto.

Embora teoricamente não haja pressa para a aprovação dessa reforma, já que para vigorar nas Eleições, qualquer alteração legal precisa obedecer o princípio da anualidade, ou seja, ser promulgada um ano antes do pleito eleitoral, tem-se que a reserva de assento, no Brasil, só venha a ser possível, caso aprovada, nas Eleições de 2018, tendo, para tanto, até o dia 07 de outubro de 2017 para ser promulgada.

Cabíveis, ainda, algumas observações ao voto em separado do deputado Evandro Gussi. Os votos não deixarão de ser igualitários. Candidata com 100 votos assumirá um assento com 100 votos. Seus votos não serão computados acima ou em dobro, por exemplo. Ela apenas terá direito ao assento com menos votos, o que, no entanto, não macula o voto dado a um candidato que não se elegeu, embora com mais votos que a mulher que assumiu o assento. Se assim fosse, o sistema proporcional, ao qual o deputado inclusive, concorreu, seria o mais injusto de todos, pois é sabido que candidato de determinado partido que faz milhares ou até milhão de votos tem possibilidade de dar assentos a seus colegas de partido, como é bem conhecido o caso do deputado federal Enéas Carneiro $^{8}$ e, mais recentemente, do deputado federal Tiririca' ${ }^{9}$ São os popularmente chamados 'puxadores de

\footnotetext{
${ }^{8}$ No ano de 2002, Enéas Carneiro foi eleito pelo Partido Prona, para o cargo de deputado federal, com a maior votação já registrada na história do Brasil para o cargo. Após diversas tentativas de se eleger presidente com apenas 30 segundos de tempo de propaganda eleitoral, Enéas não apenas se elegeu em 2002 como deputado federal, mas diante do sistema proporcional, que considera os votos dado ao partido, "levou com ele" para a Câmara outros colegas de partido. Assim noticiou, à época, uma revista de circulação nacional no Brasil, a Superinteressante, Edição 182, de novembro de 2002: Um milhão, quinhentos e setenta e três mil, cento e doze. Com essa assombrosa quantidade de votos, os paulistas elegeram o deputado federal mais votado da história. Quando divulgado, o recorde não foi motivo de comemoração, mas de constrangimento. O cardiologista Enéas Carneiro, do Partido da Reedificação da Ordem Nacional (PRONA), acabava de conseguir seis vagas na Câmara dos Deputados. Uma para ele e mais cinco para candidados do seu partido - quatro dos quais não tiveram mais de mil votos. Disponível em: < http://super.abril.com.br/cultura/o-perigo-real-de-eneas>, Acesso em: 26 fev 2016.

${ }^{9} \mathrm{O}$ palhaço Tiririca, personagem do senhor Francisco Everardo Oliveira Silva, novamente veio abalar o sistema proporcional no ano de 2010, ao ter a segunda maior votação histórica para a Câmara dos Deputados. Com aproximados 1,35 milhões de votos, levou mais quatro deputados para a Casa Legislativa. Disponível em: < http://eleicoes.uol.com.br/2010/sao-paulo/ultimasnoticias/2010/10/03/com-mais-de-13-milhao-de-votos-tiririca-e-deputado-mais-votado-do-pais-e-deve-levar-mais-4.jhtm>, acesso em 26 fev 2016.
} 
voto'. Muitos candidatos com mais votos nominais pelo sistema proporcional não foram eleitos, ao passo que candidatos com poucos votos foram beneficiados pelas votações estratosféricas de seus colegas de partido. ${ }^{10}$

Sobre a PEC 134/2015 existe a oposição argumentando valor desigual do voto, argumento improcedente, portanto, já que, apesar de várias manifestações contra o sistema proporcional para cargos às Casas Legislativas no Brasil, em diversas oportunidades o legislador deixou de modificar o sistema, não o tendo feito, inclusive, quando da última reforma eleitoral, promulgada em 29 de setembro de 2015, Lei n. 13.165/2015.

Sob o viés da igualdade, o legislador em comento está considerando apenas o aspecto formal da mesma, desconsiderando o caráter material atribuído a tal princípio, assunto este já explanado no decorrer do presente artigo.

As ações afirmativas são consideradas, por muitos, injustas, pois visam favorecer um determinado seguimento. Não vêem seus opositores, no entanto, que para um mundo com mais diálogo e inclusão, algumas vantagens devem ser dada aos desavantajados, muitos vezes, até mesmo, contrariados e envergonhados de sua posição. Quantos não se envergonharam por ser pobres, ou por serem de determinada etnia, ou mesmo, por serem mulheres em meio a um ambiente tradicionalmente masculino.

Não sem custo e sem luta será mudado o perfil dos políticos brasileiros, considerando que falta, a alguns legisladores, uma visão, a medida do possível, omnisciente do Brasil, além de um perspectiva comparativa com o direito internacional.

\section{CONCLUSÃO}

É árduo caminho percorrido pelas mulheres para emancipação nas esferas públicas e privadas, nota-se que ainda há longo caminho a galgar rumo à igualdade material política. Mesmo com inúmeras ações afirmativas que utilizam cotas inclusivas já em ação no Brasil, a tentativa de integrar mulheres na política partidária ainda encontra resistência, pautadas em justificativas diversas. Isto pode novamente obstruir, para as Eleições do ano de 2018, um passo rumo a uma inserção maior feminina nas cadeiras legislativas.

É viável que as mulheres possam aumentar a voz nos Parlamentos e este artigo veio analisar o quão ameaçada está a Emenda Constitucional proposta e aprovada. A tarefa de pressionar por esta mudança, inclusive antes do próximo pleito a ser realizado no ano de 2018, cabe a todos aqueles preocupados com a questão da inclusão social, para que sejam amenizadas algumas discrepâncias existentes não apenas no Brasil, mas também em outras democracias como relatado.

\footnotetext{
${ }^{10}$ Nas eleições para Deputado Federal no ano de 2010, apenas 36, dos 513 deputados, foram eleitos com seus próprios votos, ao passo que os outros 477 foram "puxados" por votos dados à legenda ou a outros candidatos de seu partido ou coligação. Disponível em: <http://www2.camara.leg.br/camaranoticias/noticias/POLITICA/475535-APENAS-36-DEPUTADOS-SE-ELEGERAMCOM-SEUS-PROPRIOS-VOTOS.html> acesso em 26 fev 2016.
} 
Analisa se que não há o perder com as cotas de assento; apenas o que se ganhar. No atual quadro brasileiro, os partidos políticos devem ter entre seus candidatos mínimo de 30\% de cada gênero, conforme já exposto. Com esta inovação, e a garantia de um mínimo de assento nas casas legislativas, mais mulheres se disporão a sair candidatas, e os partidos não terão tanta dificuldade em preencher as vagas destinadas a elas. Todos ganham. Partidos, homens, mulheres, sociedade e Nação.

É possível considerar, por exemplo, uma vigência por 20 anos ou algo próximo disto, para este sistema de cotas, assim poderá ocorrer um equilíbrio no sistema, evitando a longo prazo também distorções.

Não se trata de dar a cota para a mulher por considerá-la inferior ou incapaz de concorrer em igualdade, mas sim de quebrar a barreira psicológica ainda existente para a maioria das mulheres de que apenas homens podem fazer política, conforme por anos alguns estudiosos podem ter afirmado. A partir do momento em que for ampliada a oportunidade da mulher se eleger, o medo da derrota será diminuído incentivando mais mulheres a quebrar a barreira do ambiente doméstico e privado, migrando, ainda que gradual e sensivelmente, para o público.

\title{
FROM HOUSE TO CONGRESS - WOMEN'S INSERTION IN POLITICAL PARTIES: AFIRMATIVE ACTIONS TOWARDS FEMININE INCLUSION IN PARLIAMENTS
}

\begin{abstract}
The article treats about female participation in political parties in democratic nations, particularly in Brazil. It ranges from women's emancipation in the last two centuries to nowadays, passing through social ascension, emphasizing the increasing role in the politics of the country, being an elector or a candidate. Legally there is no gender difference anymore concerning the rights women possess by comparing to men's ones; though their participation in elections is not yet satisfactory, as just a few of them, when candidates, are elected. The article, then, brings affirmative actions as a way to promote material equality, by including more women in Parliaments. The methods in the text are the inductive, deductive, regressive analytical and bibliography.
\end{abstract}

Keywords: Political rights. Women. Participation. Law. Inclusion.

\section{REFERENCIAS}

ALVES, Fernando de Brito. Constituição e Participação Popular. A construção histórico-discursiva do conteúdo jurídico-políticos da democracia como direito fundamental. Curitiba: Juruá, 2013.

Os horizontes de Prometeu: Cidadania e Direitos Fundamentais em países de modernidade tardia. In.: KLOCK, Andrea Bulgakov; CAMBI, Eduardo Augusto Salomão; ALVES, Fernando de Brito (Orgs.). Direitos Fundamentais Revisitados. Curitiba: Juruá, 2008. P. 265-286.

AMÂNCIO, Kerley Cristina Braz. "Lobby do Batom": uma mobilização por direitos das mulheres. Revista Trilhas da História, Três Lagoas, v.3, n. 5 jul-dez, p. 72-85. 2013. 
Apenas 36 deputados se elegeram com seus próprios votos. In.: Câmara dos Deputados, 2014. Disponível em http://www2.camara.leg.br/camaranoticias/noticias/POLITICA/475535-APENAS-36-DEPUTADOS-SEELEGERAM-COM-SEUS-PROPRIOS-VOTOS.html Acesso em 26 fev 2016.

ARISTÓTELES. A Política. Introdução de Ivan Lins; tradução de Nestor Silveira Chaves. Ed. Especial. Rio de Janeiro: Nova Fronteira, 2011.

BALZAC, Honoré de. A mulher de trinta anos. Tradução de Marques Rebelo. Ed. Especial. Rio de Janeiro: Nova Fronteira, 2013.

BASTOS, Celso Ribeiro. Hermenêutica e Interpretação Constitucional. 4a edição, São Paulo: Malheiros Editores, 2014.

BELINTANI, Leila Pinheiro. "Ação Afirmativa" e os princípios do direito. As questões das cotas raciais para ingresso no ensino superior no Brasil. Rio de Janeiro: Lumen Juris. 2006.

BERTONCINI, Carla; PADILHA, Elisangela. Família, dignidade da pessoa humana e relativismo cultural. Revista Direitos Humanos e Democracia. Ed. Unijuí. Ano 5, n. 9, p.306-330, jan-jun. 2017.

BRASIL. Lei n. 3.071, de 01.01.1916. Código Civil dos Estados Unidos do Brasil. Disponível em: http://www.planalto.gov.br/ccivil_03/leis/L3071.htm Acesso em 28 fev 2016.

Lei n. 4.121, de 27.08.1962. Dispõe sôbre a situação jurídica da mulher casada. Disponível em: http://www.planalto.gov.br/ccivil_03/leis/1950-1969/L4121.htm Acesso em 28 fev 2016.

Lei n. 9.100, de 29.09.1995. Estabelece normas para realização de Eleições Municipais de 3 de outubro de 1996, e dá outras providências. Disponível em: http://www.planalto.gov.br/ccivil_03/leis/L9100.htm Acesso em: 24 jan 2016.

Lei n. 9.504, de 30.09.1997. Estabelece normas para as eleições. Disponível em: http://www.planalto.gov.br/ccivil_03/leis/L9504.htm Acesso em: 24 jan 2016.

Lei n. 10.406, de 10.01.2002. Institui o Código Civil. Disponível em: http://www.planalto.gov.br/ccivil_03/leis/2002/L10406.htm Acesso em 28 fev 2016.

Lei n. 11.340, de 07.08.2006. Cria mecanismos para coibir a violência doméstica e familiar contra a mulher, nos termos do $\$ 8^{\circ}$ do art. 226 da Constituição Federal, da Convenção sobre a Eliminação de Todas as Formas de Discriminação contra as Mulheres e da Convenção Interarmericana para Prevenir, Punir e Erradicar a Violência contra a Mulher; dispõe sobre a criação dos Juizados de Violência Doméstica e Familiar contra a Mulher; altera o Código de Processo Penal, o Código Penal e a Lei de Execução Penal; e dá outras providências. Disponível em: http://www.planalto.gov.br/ccivil_03/_ato2004-2006/2006/lei/111340.htm Acesso em 19 jan 2016.

Lei n. 12.034, de 29 de setembro de 2009. Altera as Leis n. 9.096, de 19 de setembro de 1995 - Lei dos Partidos Políticos, 9.504, de 30 de setembro de 1997, que estabelece normas para as eleições, e 4.737, de 15 de julho de 1965 - Código Eleitoral. Disponível: http://www.planalto.gov.br/ccivil_03/_ato20072010/2009/lei/112034.htm Acesso em 19 jan 2016.

CABRA, Guilherme Perez. Educação e Democracia: perspectiva emancipatória a partir da filosofia social de John Dewey. Revista Quaestio Iuris, Rio de Janeiro, v. 10, n. 2, p. 844-866, 2017.

COMPARATO, Fabio Konder. Ensaio sobre o juízo de Constitucionalidade de políticas públicas. Revista de Informação Legislativa. Brasília, a 35. n. 138, p. 39-48, abr/jun2010. 
COSTA, Ilton Garcia da; NAVAS, Ana Paula Pavanini. Multa criminal, sua Inadimplência e a Exclusão Social pelo Impedimento em Restabelecer Direitos Políticos. Revista Brasileira de Ciências Criminais, São Paulo, ano 24, vol. 125, p. $81-102$, nov. 2016.

COSTA, Ilton Garcia da; NAVAS, Ana Paula Pavanini. SANTIN, Valter Foleto (Org.) . Organizações Sociais, efetivaçôes e inclusão social. 1. ed. São Paulo: Editora Verbatim, 2014.

ELLEN Gracie: a trajetória de uma década da primeira mulher a integrar o STF. IN.: SUPREMO TRIBUNAL FEDERAL, 2011. Disponível: http://www.stf.jus.br/portal/cms/verNoticiaDetalhe.asp?idConteudo=185964 Acesso em: 28 jan 2016.

FERREIRA FILHO, Manoel Gonçalves. Direitos Humanos Fundamentais, 14 ed. São Paulo: Saraiva, 2012.

GIACOIA, Gilberto. Justiça e Dignidade. Revista Argumenta (FUNDINOPI), Jacarezinho, v. 2, n.1, p. 11-31, 2002.

GOMES, José Jairo. Direito Eleitoral. 11 ed. São Paulo: Editora Atlas, 2015.

KELLY, Paul et al. O Livro da Política. Tradução de Rafael Longo. São Paulo: Globo, 2013.

KYMLICKA, Will. Filosofia Política Contemporânea: uma introdução. Tradução de Luís Carlos Borges; revisão da tradução Marylene Pinto Michael. São Paulo: Martins Fontes, 2006.

LA PARITÉ politique. In.: VIE PUBLIQUE. Au coeur du débat public, 2011. Disponível em: http://www.viepublique.fr/politiques-publiques/droits-femmes/parite-politique/. Acesso em: 24 jan. 2016.

LÉRIAS, Reinéro Antonio. As Constituições Brasileiras: direitos fundamentais e cidadania. In.: KLOCK, Andrea Bulgakov; CAMBI, Eduardo Augusto Salomão; ALVES, Fernando de Brito (Orgs.). Direitos Fundamentais Revisitados. Curitiba: Juruá, 2008. P. 191-264.

LIMA, Jairo Néia. Direito Fundamental à Inclusão Social. Eficácia Prestacional na Relações Privadas. Curitiba: Juruá, 2012.

LOPES, Aline Luciane. A Mulher e a Construção da Cidadania na Perspectiva dos Direitos Humanos. Revista Argumenta - UENP, Jacarezinho, PR, n. 15, p. 223-237, 2011.

Mais mulheres na política. em: http://www2.senado.leg.br/bdsf/bitstream/handle/id/510155/Livro\%20-

\%20Mulheres\%20na\%20Politica.pdf?sequence=1 Acesso em: 11 fev 2016.

MULHERES na Política. In.: PORTAL BRASIL, 2012. Disponível em: http://www.brasil.gov.br/cidadania-ejustica/2012/02/mulheres-na-politica Acesso em: 24 jan 2016.

PEC 98/2015. Disponível em: http://www.senado.leg.br/atividade/rotinas/materia/getPDF.asp?t=171440\&tp=1. Acesso em: 28 jan 2016.

PEC 134/2015. Disponível em: http://www2.camara.leg.br/proposicoesWeb/prop_mostrarintegra;jsessionid=05F0E8C866B49CE218A5634 DFBB3D2C1.proposicoesWeb1?codteor=1390870\&filename=Avulso+-PEC+134/201 . Acesso em: 14 fev 
2017.

PINTO, Céli Regina Jardim. Feminismo, História e Poder. Revista de Sociologia e Política, Curitiba, v. 18, n. 36, p. 15-23, jun. 2010.

Uma mulher "recatada": a deputada Suely de Oliveira (1950-1974). Topoi (Rio J.), Rio de Janeiro, vol. 15 , n. 29, p. 565-587, jul./dez. 2014.

POCHMANN, Marcio et al.(Orgs.). Atlas da Exclusão Social: agenda não liberal da inclusão social no Brasil. São Paulo: Cortez, 2005, v. 5.

Saiba quem é Malala Yousafzai, a paquistanesa que desafiou os talibãs. In.: TODOS PELA EDUCAÇÃO, 2014. Disponível em http://www.todospelaeducacao.org.br/educacao-na-midia/indice/31560/saiba-quem-e-malalayousafzai-a-paquistanesa-que-desafiou-os-talibas/ Acesso em 19 jan 2016.

SANDEL, Michael J. Justiça. O que é fazer a coisa certa. Tradução de Heloísa Matias e Maria Alice Máximo. 12 ed. Rio de Janeiro: Civilização Brasileira, 2013.

SANTOS, Boaventura de Sousa. Pela Mão de Alice. O social e o político na Pós-Modernidade. 14 ed. São Paulo: Cortez, 2013.

SARTRE, Jean-Paul. L'existencialisme est un humanisme. France: Éditions Gallimard, 1996.

SOBOTTKA, Emil Albert. Democracia e Desigualdade Social. In.: BOMBASSARO, Luiz Carlos; KRÜGGELER Thomas; SOUZA, Ricardo Timm de (Orgs.). Democracia e Inclusão Social. Desigualdade como desafio para a sociedade e a Igreja no Brasil. Porto Alegre: EDIPUCRS, 2009. P. 153-165.

SOBRE a Lei Maria da Penha. In.: CNJ, Conselho Nacional de Justiça. 2016. Disponível em: http://www.cnj.jus.br/programas-e-acoes/lei-maria-da-penha/sobre-a-lei-maria-da-penha. Acesso em: 19 jan. 2016.

SPINOZA, Baruch de. Tratado Político. Tradução e Prefácio de José Pérez. Ed. Especial. Rio de Janeiro: Nova Fronteira, 2013.

THOMÉ, Candy Florencio; SCHWARZ, Rodrigo Garcia. The principle of gender equality and the fundamental rights and guarantees of participation of women in union organizations in Brazil. Revista Quaestio Iuris, Rio de Janeiro, v. 10, n. 2, p. 675-704, 2017.

VAZ, Gislene de Almeida. A participação da mulher na política brasileira: A Lei de Cotas. 2008. 65 F. Monografia (Especialização). Centro de Formação, Treinamento e Aperfeiçoamento (Cefor), da Câmara dos Deputados, Curso de Especialização em Processo Legislativo, Brasilia, 2008.

WEYNE, Bruno Cunha. O Princípio da Dignidade Humana. Reflexões a partir da filosofia de Kant, São Paulo: Editora Saraiva, 2013.

XIFRA-HERAS, Jorge. A Informação: análise de uma liberdade frustrada. São Paulo: Edusp, 1975.

Trabalho enviado em 07 de março de 2017.

Aceito em 04 de julho de 2017. 
